\title{
Literature in the Language Classroom: Roles and Pedagogy
}

Bal Ram Adhikari

\begin{abstract}
The present article is theoretical in nature with its prime focus on the pedagogical dimension of literature in the language classroom in general and the ESL/EFL classroom in particular. It draws on some of the key publications in the field and my experience in English language education as a teacher and material developer. Moreover, I have drawn some evidence from B. Ed. and M. Ed. English courses offered to prospective teachers, and their class observation. Divided into three sections, the article begins with a checkered history of literature in mainstream language teaching methods while the second section underscores roles of literary texts in students' balanced language development. The final section proposes the pedagogical approach to and procedures of exploiting literary texts to maximize learning opportunities for students.
\end{abstract}

Keywords: activation, consolidation, culturally-sensitive, exploration

\section{Introduction}

To begin with, there is little consensus as to the place of literary texts in the second language classroom and its contribution to learners' overall language development. Maley (2001) observes that "the role of literature in language teaching remains contentious, owing to widespread differences in interpretation of the precise nature of that role" (p. 180). Even from the cursory survey of language teaching methods in the past, we can see that the use of literature as a means of developing learners' language has a checkered history. To go back in the history, the Grammar Translation Method in the late $19^{\text {th }}$ century privileged literary texts in the language classroom with its unshakable belief that engaging students to translate the passage excerpted from target literary work contributes to the development of their vocabulary and grammatical structures (Larsen-Freeman \& Anderson, 2011). Even in the GT Method the use of content from the literary text and deeper interpretation of literary devices were not the primary concern of the teacher. Literary texts were recognized only as a means to expose students to vocabulary and grammar structures and practice for translation.

The methods that emerged in the early and mid 20th centuries, namely the Direct Method and the Audiolingual Method, not only questioned the value of using literary texts, but also discouraged "use of the mother tongue in the classroom" (Richards \& Schmidt, 2010, p.40) with the conclusion that the use of translation detrimental to the development of students' L2 competence. The criticism came as a fatal blow to those who would regard literary texts as a rich linguistic and cultural resource for second language students. The theoretical principles underlying these methods themselves stood barriers to the use of literary texts with language class. With its strong foundation on structuralism, the Audiolingual Method, for instance, was guided by the theory of language as "a system of structurally related elements for encoding of meaning" (Richards \& Rodgers, 2001, p.55), that is, it took language as a totality of discrete units. Quite contrary to this, literature works on the assumption that language is primarily what it is in its 
totality. The use of literature with language students calls for adoption of a holistic rather than atomistic approach to language.

The Communicative Approach that came in the late 1970s as a reaction against Audiolingualism and as a response to second language students' needs showed the lenient attitude towards the use of literary texts in the language classroom, which reopened the previously blocked path for literature. The approach privileged the use of authentic texts, and the techniques of role-playing and strip stories (LarsenFreeman \& Anderson, 2011). Undoubtedly, literature is one of many genres, probably the richest and most versatile sources of authentic texts. Meaning, language teachers could turn to literature for authentic texts. Likewise, the Approach also opened avenues for using short dramatic texts for dramatization techniques such as role-playing, simulation, skits and short stories for role-playing, and strip-story. The strong version of the Communicative Approach, which, according to Holliday (2010, p. 168), presents text as discourse rather than a collection of functions and exponents and encourages students to communicative with text, rightly acknowledges the use of literary texts with language students. Moreover, the use of literary texts compensates for the poverty of content that the structurally-guided methods and the weak version of communicative approach suffer. Similarly, content-based instruction, one of the strong versions of the communicative approach, brings content to the fore with the assumption that medium (i.e. language) and message (content) interact and interweave with each other and hence inseparable. It is impossible for students to be communicatively competent unless they "master language and content" (Larsen-Freeman \& Anderson, 2011, p. 139). For this, the course designers and teachers are expected to draw topics from a wider range of content areas such as Social Studies, Science and Technology, Travel and Adventure, and obviously Literature.

The foregoing discussion is the indicative of the fact that there has been revival of interest in bringing literary texts to the language classroom. In recent years, argues Hismanoglu (2005, p.53), "the role of literature as a basic component and source of authentic texts of the language curriculum rather than an ultimate aim of English instruction has been gaining momentum". O'Sullivan makes a similar observation:

Current approaches have endeavored to reexamine the value of literature and have begun to uphold its worth again. These approaches assert the value of literature teaching from several aspects, primarily, literature as an agent for language development and improvement, cultural enhancement and also for the eminence that many poets have previously ascribed to it. (1991, p.2)

It is, therefore, rather than getting entangled in the sterile debate of whether to use literature for students' development, the focus has shifted to how to best exploit this most creative and critical genre of language to facilitate teaching, expedite learning process and to maximize the learning outcome.

\section{Methodology}

I have mainly employed secondary sources of information, for which I surveyed key publications in teaching literature such as Collie and Slater (1987), Carter and Long (1991), Maley (2001), Lazar (2009), and Bibby and Mcllroy (2013). Besides, I have used two types of primary sources of information: a) the survey of reading and literature courses prescribed for Bachelor's and Master's programs by Faculty of 
Education, Tribhuvan University; and b) class observation of 12 trainee teachers, one class of each, from the Master's Program teaching one of the B. Ed. reading courses. Both the courses and the teachers were sampled purposively. I have adopted the interpretative approach to the discussion of the issue of literature in the language class and empirical evidence collected from the survey and class observation.

\section{Reviews and Discussion}

The section subsumes the place of literary texts in present English curricula prescribed by the Department of English, Faculty of Education for prospective English teachers, which is followed by the discussion of roles of literary texts in students' language development. The second part of the discussion presents an approach to and pedagogy of using literary texts in language class.

\section{Place of Literature in English Curricula and its Role in Language Learning}

Talking about the Nepalese context, the English courses from school to university levels strongly exhibit the feature of content-based courses in which literature as a source of texts has dominated other areas. To substantiate the argument, I present evidence from English courses offered to B. Ed. and M. Ed. students under Faculty of Education, Tribhuvan University. The courses, namely General English, Reading, Writing and Critical Thinking (B. Ed. $1^{\text {st }}$ year), Expanding Horizons in English (B. Ed. $2^{\text {nd }}$ year), Critical Readings in English (B. Ed. $3^{\text {rd }}$ Year), Literature for Language Development (B. Ed. $4^{\text {th }}$ year), Interdisciplinary Readings (M. Ed. $1^{\text {st }}$ semester), Readings in English (M. Ed. $2^{\text {nd }}$ semester), and Readings in Literary Genres (M. Ed. $3^{\text {rd }}$ semester) are heavily based on English literatures around the globe. Five out of thirteen English courses offered to prospective secondary English teachers privilege reading in general and reading literary texts in particular. Similarly, three English courses out of sixteen in the Master's program are strongly rooted in literary writings that represent a variety of Englishes from diverse "geographical locations such as Britain, the United States of America, South Africa, India and Nepal" (Awasthi, Bhattarai \& Rai, 2015, para.3 ). The curricula of the both levels have welcomed literature as one of the feeding disciplines. Furthermore, in some cases literature is the only discipline to feed the courses. The courses, namely Literature for Language Development and Readings in Literary Genres can be a case in point.

The study of the objectives indicates that these courses expect students to a) process the prescribed texts (reading) and produce their own texts (writing); b) resist or conform to the writer's stance/ideology; c) give continuity to writer's thought or create their own; d) reflect on and refract the text; e) and f) move from the role of recipient to that of the creator of text (Adhikari, 2017). By and large, the curricula are strongly guided by the assumption that it is inevitable to expose students to reading texts, particularly literary ones, to enhance their English proficiency in reading and writing backed up by vocabulary and grammar. At this point, I argue that literary texts are probably the most authentic means to integrate language and content, and engage students in creative and critical use of language. The following theoretical observations further substantiate this argument.

Recognizing benign effects of literature on the language learning process, Collie and Slater (1987) and Lazar (2009) advance a number of reasons for using thoughtfully-selected literary texts with language class. Collie and Slater posit that literary texts are the valuable material that provides students with genuine 
and undistorted language, and such texts serve the indirect route to experiencing target culture norms and values. The latter contribute to the students' understanding of cultural aspects of the language. Other reasons put forward are language enrichment and personal development. In a similar spirit, Lazar (2009) recognizes literature as a highly motivating material for its intrinsic quality to "expose students to complex themes and fresh, unexpected uses of language" (p.15). For Lazar, encouraging language acquisition is another important reason that justifies the presence of literature in the second language classroom. Literature, according to him, can compensate student's scanty exposure to spoken language and stimulate language acquisition by providing "meaningful and memorable contexts for processing and interpreting new language" (p. 17). Further reasons as advanced by Lazar that justify the use of literary writings are expanding students' language awareness, developing their interpretative abilities, and educating the whole person. Likewise, Maley (2001) draws on the writers such as Billows (1961), McRae (1991), Carter and Long (1991), and Kramsch (1993) and comes to the conclusion that "the rational for incorporating literature is [...] well established" (p.182). Maley maintains that unlike referential texts whose primary function is to convey information and requires the reader to receive and process the information, representational texts whose primary function is to represent the writer's inner world thereby requires "the reader to re-creative in his or her own terms the imaginative world of the text" (p. 182). What is implied in Maley's observation is that literary texts raise the reader from the position of recipient of information and initiates him/her into text (re)creation. Against this backdrop, I present some of the arguments that further support the rationale for using literature with language students.

By its very nature, literature is likely to expand students' language and content knowledge immensely. It is because a well-written literary text is linguistically rich, culturally sensitive, cognitively challenging and affectively engaging. This argument underlines four facets of literary writing that appeal to language students and teachers alike. They are richness of language, cultural-embeddedness, interpretation, and affect.

So much is probably obvious that what makes a writing literary and what distinguishes it from the non-literary one is its language. To expose second language students to a literary writing is to expose them to figures of speech such as metaphor, simile, personification, hyperbole, allegory, irony, metonymy, onomatopoeia, paradox, parody, pun, sarcasm, and satire, apart from idioms, collocations, proverbs and sayings. Literature demonstrates how sentence structures can be intentionally manipulated to create special effects on readers. Moreover, literature maximizes opportunities for students to feel inherent musicality of language through prosodic features such as rhythm, rhyme, alliteration and assonance. Literature in general and poetry in particular is arguably the best pedagogical resource to restore musicality inherent in each language. By nature, poetry is oral and it comes to life through music. Celce-Murcia and Hilles (1988) rightly posit that "poetry in the ESL classroom can revive our love and respect for English and can bring to mind again the joy and exquisite beauty of the language" (p. 116). Lexical, syntactic and phonological properties of a literary text save students from language deprivation.

Literature as a type of discourse "reflects the social, epistemological and rhetorical practices of a 
specific group" (Jolliffe, 2001, p. 102). According to this proposition, literature is the reflective of sociocultural practices, cultural assumptions, values, myths, and histories, which serves as the means to get insights into the target culture. Bibby and Mcllroy (2013) refer to Scott (1964) who considers literature as a cultural way in. Engaging students in literary texts thus helps them "to understand and appreciate cultures and ideologies different from their own in time and space" (Carter and Long, 1991, p. 2). Such understanding is instrumental in exploring similarities and differences between target culture and their own. This helps in enhancing cultural sensitivity and expanding "sphere of interculturality" (Kramsch, 1993, p.82) of students. Moreover, literary texts can be used to cultivate and develop four types of senses indentified by Adaskou, Britten and Fahsi (1990), namely "aesthetic sense" through the appreciation of artistic manipulation of language, "the sociological sense" through the information about target customs, institutions, history and myths, "semantic sense" through the interpretation of content, and "pragmatic sense" through the interpretation of interaction between language and context.

From the perspective of interpretation, literature is cognitively challenging, since it requires students to read not only the lines (i.e. understanding information), but also between the lines (i.e. making inferences), and beyond the lines (i.e. connecting one's understanding and inference to geo-political, and cultural contexts). Literary interpretation is a cognitive process, posits Simon (1995), because it concerns "the meanings of, in, and evoked by literary texts". Simon further argues that "enormous thought goes into the production of texts and perhaps even more (given the ratio of readers to writers) into interpreting them" (first para.). The process turns out to be more daunting and complex when students are reading and interpreting literature across languages. Lazar (2009) asserts that "literary texts are often rich in multiple levels of meaning, and demand that the reader/learner is actively involved in 'testing out' the unstated implications and assumptions of the text" (p. 19). Interpretation requires readers to enter into the textual world and the author's consciousness through the processes of evocation, prediction, and activation of one's schema.

Literature is affectively engaging owing to its quality to arouse feelings and emotions in readers. The author invites readers to share the world he/she has created or referred to through words. It is through feelings and emotions that readers indentify with and move towards the author's world. Like the author, the reader should be imaginative to make his/her entry into and finally dwell in the textual world. Unless the reader is emotionally engaged, the deeper understanding of literary texts is not possible. More than this, through such engagement, the reader is also in the constant process of recreating the author's world through and in his/her own language.

The common thread that runs through the foregoing discussion is that literature is too important to be ignored in the second language classroom. Students benefit from literary texts in several ways as outlined above. In this regard, pedagogy has a vital role to play, since it the pedagogy that determines the extent to which students can exploit literary resources for their benefit.

\section{Pedagogy: Approaches and Procedures}

Under pedagogy I discuss the approach and procedures of exploiting literary texts to maximize 


\section{learning opportunities.}

As an external supervisor, I observed 12 classes of trainee teachers, one class of each, from 1 to 3 May2018. The trainee teachers from the Master's Programme were teaching one of the English reading courses to B. Ed. students. All the teachers showed their high temptation to explain the text from the outset of the lesson, with nominal and in some cases null engagement of students in pre- and post-reading activities. The students did minimum amount of reading of the text. They were reduced to listeners of the teacher's lecture. Consequently, there was low student participation and engagement and the students' contribution to learning and teaching remained on the fringe. Such an approach to reading is detrimental to students' overall language development, and hence calls for rethinking.

As an alternative to the explanatory approach, I have been following the student-centred, exploratory, collaborative and integrated approach. This approach is informed by "enlightened eclecticism" (Brown, 2002), "thinking classroom" (Crawford, Saul, Mathews \& Makinster, 2005), "an eclectic approach" (Cowan, 2008) and "principled eclecticism" (Larsen-Freeman \& Anderson, 2011). The underlying assumption of this approach is that the teacher should resort to different approaches and make use of their strengths to expedite teaching-learning process and maximize the learning outcome. What follows is a brief explanation of the proposed approach.

Centrality of Students: Reading is the most prioritized skill in teaching language through literature. By implication, students are expected to get engaged in the text primarily through reading. They must be reading actively, imaginatively, creatively and even critically rather than listening to the teacher's explanation. For the pedagogy of literature to yield fruitful result, students should be taken as the point of reference.

Exploration: Bringing students to the fore of teaching and learning is giving more value to exploration than explanation. While dealing with literary texts in the classroom, teachers are often tempted to giving a long explanation about the theme, characters, plot, figures of speech and so on which ultimately discourages students from digging into the text themselves. Explanation should be kept to the minimum for two reasons. First, it discourages active student involvement in classroom activities. Second, it distorts aesthetics that students can experience from exploring language and theme of the text (Adhikari, 2011). Textual exploration calls for a greater degree of mental processing, and the language deeply processed by students themselves is more memorable than that is simply served by the teacher.

Collaboration: Collaboration maximizes learning opportunities. It is one of the best ways of inviting individual students to make contribution to teaching and learning process. Two levels of collaboration can be envisaged and practiced. The first is the collaboration between teacher and students in which students can work with the teacher in researching into such areas as the author's background, historical and cultural settings of the text, and locating different interpretations of the text on the Internet and presenting some of them in the classroom. The second level of collaboration is among students. Students can work in a small group of three or four in such tasks as preparing the glossary, acting out the dialogues from the text, and writing their own dialogues and acting them out. 
Integration: The approach to the use of literature in the language classroom should prioritize integration of language skills, and integration of skills and language components. Though primary orientation of literary texts is reading, this skill has to be integrated with writing, speaking and listening for balanced language development. Moreover, it is equally essential to integrate vocabulary and grammar with these skills. Such integration is instrumental in developing students' language organically.

The approach outlined above is normally actualized through the three-stage procedure that goes by different names such as pre-reading, while-reading and post-reading (Lazar, 2009; Hedge, 2000 ); anticipation, building knowledge and consolidation (Crawford, Saul, Mathews and Makinster, 2005), and engage, study and activate (Harmer, 2007). Collie and Slater (1987), however, recommend a four phase procedure entailing first encounters, maintaining momentum, exploiting highlights, and endings. It implies that the pedagogy of literature in the language classroom can draw upon the general reading pedagogy. Of the possible procedural options, I loosely draw on Crawford et al.'s (2005) framework with slight modification i.e. activation (instead of anticipation), building language and knowledge and consolidation. In what follows, I present each stage with commonly used activities.

\section{Activation}

It is essential that teachers respect and capitalize on students' experiences, knowledge and language resources. Students bring to class a wealth of experiences of oral as well as written literature from their first languages and also from the target language. We need to value their linguistic, cultural and literary possessions by giving ample space in and beyond the classroom. Activation of the existing knowledge provides a context for understanding language and ideas when they encounter the text later. Moreover, it also informally assesses what students already know, including their misconceptions. Moreover, helping students to get cultural background of and stimulating them in the text (Lazar, 2009, p.83) are other key reasons for engaging students in activation activities. We can propose a wide range of such activities to orient students to the text. Some of them can be: working with the pictures; digging into the title; sharing their knowledge about the topic; previewing the title; predicting the theme; contextualization questions; personalization questions; preparing their own glossary of the text; reading the glossary given in the text; relating the text to their first language reading experiences; and concept teaching (but avoiding the summary).

\section{Building Language and Knowledge}

This stage requires students to deal with the text so as to enrich their language and content knowledge. Students are engaged in the exploration of the text individually or collaboratively through such activities as coding the text (underlining, and writing the meanings), responding to comprehension-checking questions, and identifying main points. The exploratory and collaborative activities encourage deeper processing of content and language. Other possible activities that provoke direct interaction with the text are: "readdiscuss-write and share (RDWS)" (Adhikari, 2010, p. 6), jigsaw reading, questioning and answering in groups, completing the graphic organizers, multiple choice, and true/false items. 


\section{Consolidation}

Consolidation activities take students beyond the text by engaging them in writing and speaking activities such as reflecting on the theme, sharing their opinions, agreeing or disagreeing with the writer's stance, identifying with characters, and creating a parallel text (writing a similar poem, story, conversation). These activities integrate reading into writing and speaking. To accomplish the tasks, students need to interact not only with the text but also with themselves. For this the teacher needs to set the tasks that require students to read between and beyond the lines. Students should reflect on what they have learned. They can also summarize main ideas in their own words; interpret the main ideas from their own perspectives; and critically appreciate the text. Additional activities for consolidation of students' language and content knowledge are: Did you like...? Why?, writing across the genres (a poem into a paragraph, a paragraph into a poem, a story into a play, a play into a story), writing an email to the writer/character, role-play, simulation, the Internet-integrated activities such as listening to the poem on YouTube, and searching Wikipedia for additional information about the author.

It is hard to make an exhaustive list of the activities for each of these stages. Teachers can also devise their own activities as per the demand of teaching-learning context. The choice of activities is subject to such factors as level of students, nature of the text, time available for the lesson and students' expectations.

The first and third stages require students to interact mainly with their own selves by exploring their previous learning, assumptions and views while the second stage calls for interaction with the text. These two modes of interaction are engaging and promote active participation. Most importantly, they provide students with opportunity to practice their agency.

\section{Conclusion and Implications}

Language teaching methods differ in terms of their perception of literary texts and the roles they assign to the latter in the development of students' language. Such differences, as in the past, will remain in the future too. However, the presence of literature is being more and more conspicuous in the contemporary language classroom with the realization that literary writing is one of the richest resources for students to get access to the target language and culture. This resource exhibits linguistic richness, cultural sensitivity, poses cognitive challenge to students, and engages them emotionally provided that the pedagogy is studentcentered, exploratory, collaborative and integrated.

It is equally important that the pedagogy activate students' inner resources, enrich their content and language, and provide them with opportunity to consolidate what they have learned from texts. The conjunction of literary texts and activation activities can stimulate the inner resources such as interest, motivation and memory. Furthermore, exploration of texts can contribute to language and content enrichment, and finally having students generate their own texts orally or in written form is instrumental in consolidating what they have accessed from others' texts. 


\section{References}

Adaskou, K., Britten, D. \& Fahsi, B. (1990). Design decisions on the cultural content of a secondary English course for Morocco. ELT Journal, 44(1), 3-10.

Adhikari, B. R. (2010). Teaching speaking in the Nepalese context: Problems and ways of overcoming them. Journal of NELTA, 15(1-2), 1-9.

Adhikari, B. R. (2011). English grammar for teachers: Theories and activities. Kathmandu: Oriental Publication.

Adhikari, B. R. (2017). Situating advanced reading texts in different zones of cultural experiences. Paper presented at the 22nd international conference of NELTA, Kathmandu.

Awasthi, J.R., Bhattarai, G. R. \& Rai, V. S. (Eds.) (2015). English for the new millennium. Kathmandu: Ekta Books.

Bibby, S. \& Mcllroy, T. (2013). Literature in language teaching: What, why and how. The language teacher, 37(5), 19-21.

Brown, D. (2002). English language teaching in the "post-method" era: Toward better diagnosis, treatment, and assessment. In Richards, J. C. \& Renandya, W. A. (Eds.), Methodology in language teaching: An anthology of current practice (pp.9-18). Cambridge: Cambridge University Press.

Carter, R. A. \& Long, M. N. (1991). Teaching literature. London: Longman.

Celce-Murcia, M. \& Hilles, S. (1988). Techniques and resources in teaching grammar. Oxford. Oxford University Press.

Collie, J. \& Slater, S. (1987). Literature in the language classroom. Cambridge: Cambridge University Press

Cowan, R. (2008). The teachers' grammar of English. Cambridge: Cambridge University Press.

Crawford, A. Saul, E. W. Mathews, S. \& Makinster, J. (2005). Teaching and learning strategies for thinking classroom. Kathmandu: Alliance for Social Dialogue.

Dean's Office (2015). Courses of four year B. Ed. annual system. Kirtipur: Dean's Office, Faculty of Education.

Dean's Office (2015). Master of education in English: Semester courses. Kirtipur: Dean's Office, Faculty of Education.

Harmer, J. (2007). The practice of English language teaching (4th ed.). London: Pearson

Hedge, T. (2000). Teaching and learning in the language classroom. Oxford: Oxford University Press.

Hismanoglu, M. (2005). Teaching English through literature. Journal language and linguistic studies, 1(1), 53-66.

Holliday, A. (2010). Appropriate methodology and social context (1th South Asian ed.). Cambridge: Cambridge University Press.

Jolliffe, D. (2001). Discourse. In Taylor,V. E. \& Winquist, C. E. (Eds.), Encyclopedia of postmodernism (pp.101-103 ). New York: Routledge.

Kramsch, C. (1993). Context and culture in language teaching. Oxford: Oxford University Press.

Larsen-Freeman, D. \& Anderson, M. (2011). Techniques \& principles in language teaching (3rd ed.). 


\section{$10 \quad$ Journal of NELTA Gandaki (JoNG) Vol. I February 2019}

Oxford: Oxford University Press.

Lazar, G. (2009). Literature and language teaching. Cambridge: Cambridge University Press.

Maley, A. (2001). Literature in the language classroom. In Carter, R. \& Nunan, D. (Eds.), The Cambridge guide to teaching English to speakers of other languages (pp.180-185). Cambridge: Cambridge University Press.

O'Sullivan, R. (1991). Literature in the language classroom. The English Teacher, XX, 1-7.

Richards, J. C. \& Rodgers, T. S. (2001). Approaches and methods in language teaching ( $2^{\text {nd }}$ ed. ). Cambridge: Cambridge University Press.

Richards, J. C. \& Schmidt (2010). Longman dictionary of language teaching and applied linguistics (4th ed.). Great Britain: Pearson Education.

Simon, H. (1995). Literary criticism: A cognitive approach [Special issue]. Stanford Humanities Review, 4 (1). Retrieved from https://web.stanford.edu/group/SHR/4-/text/simon1.html.

Bal Ram Adhikari is a lecturer in English Education at Mahendra Ratna Campus, Tahachal (TU). Mr. Adhikari has contributed to framing university courses, and designing and editing reading materials for universities in Nepal. 